\title{
Characterization of Slow Pyrolysis Wood Vinegar and Tar from Banana Wastes Biomass as Potential Organic Pesticides
}

\author{
Godfrey Omulo ${ }^{1}$, Sarah Willett ${ }^{2}$, Jeffrey Seay ${ }^{2}$, Noble Banadda ${ }^{1}$, Isa Kabenge ${ }^{1}$, Ahamada Zziwa ${ }^{1} \&$ Nicholas \\ Kiggundu $^{1}$ \\ ${ }^{1}$ Department of Biosystems and Agricultural Engineering, Makerere University, Uganda \\ ${ }^{2}$ Department of Chemical and Materials Engineering, University of Kentucky, United States \\ Correspondence: Jeffrey Seay, University of Kentucky, United States. E-mail: jeffrey.seay@uky.edu
}

Received: February 24, 2017 Accepted: April 15, $2017 \quad$ Online Published: May 31, 2017

doi:10.5539/jsd.v10n3p81

URL: https://doi.org/10.5539/jsd.v10n3p81

\begin{abstract}
Slow pyrolysis process has been used in the recent past to yield wood vinegar from various biomass wastes with a quest to investigate their chemical composition and possible uses. This study utilizes the abundant banana wastes in Uganda including leaves, pseudostem and peels (mpologoma, kisansa and kibuzi species) in the slow pyrolysis process to yield vinegar, tar and biochar. Characterization of these banana wastes' vinegar and tar fractions were investigated via chromatographic and physicochemical analysis. The principle compounds present in the banana wastes vinegar and tar as per percentage peak areas were acids (68.6\%), alcohols $(62.5 \%)$, ketones $(27.6 \%)$, phenols $(25.7 \%)$ and furans $(21.8 \%)$. The products characterization indicate that vinegar and tar contain compounds that can be used as pesticides, termiticide, fungicides, insect repellants, anti-leaching and soil degradation agents. Thus wood vinegar and tar can have sustainable impacts on agricultural sectors and chemical industries especially for developing countries.
\end{abstract}

Keywords: wood vinegar, tar, pesticides, banana wastes, characterization, bio-infrastructure, sustainable

\section{Introduction}

Banana production in Uganda is very high since it is the world's second largest producer and consumer of banana after India (UBS, 2014). According to FAO (FAO, 2013), the average annual production of banana and plantain in Uganda is approximated at 4,375,000 metric tonnes. The production of banana in Uganda varies with regions. Omulo et al. (2015) noted that all the regions of the country produce substantial amount of banana. Thus, due to this vast production of banana in Uganda, large quantities of banana wastes, including leaves, pseudostem, stalks, rejected and rotten fruits and the fruit peels are generated but without proper utilization.

Therefore, pyrolysis is the most profound modern technique that has proved effective and efficient in the energy conversion of biomass yielding various products like bio-oil, biochar and syngas (Kan, et al., 2016). Pyrolysis is a thermochemical decomposition of biomass materials at elevated temperatures and pressures but under inert or oxygen free environment (Mohan, et al., 2006), (Yorgun and Yildiz, 2015). The major advantages of pyrolysis process are the varied products that can result and the reduced environmental pollution due to minimal emission of greenhouse gases (Yorgun and Yildiz, 2015). Generally, pyrolysis process takes place at temperatures of $300-1200^{\circ} \mathrm{C}$ (Tripathi, et al., 2016) and the resultant yields depend on many factors ranging from operating conditions, biomass type among others.

Slow pyrolysis was utilized in this study to pyrolyse banana wastes. Slow pyrolysis occurs at a low heating temperature of $400^{\circ} \mathrm{C}$ and a long solids residence time causing the secondary cracking of the primary products (Brewer, et al., 2009), (Tiilikkala, et al., 2010). The major product yields include biochar up to $45 \%$ and bio-oil (vinegar and tar) about 30\% (Baimark and Niamsa, 2009), (Chalermsan and Peerapan, 2009). Lower heating rates and longer retention time enhances vapours formation from complete secondary reactions forming vinegar and tar as well as generation of carbonaceous solid biochar (Tripathi, et al., 2016).

Wood vinegar and tar, the by-products of a slow pyrolysis (carbonization), are characterized by vapour condensation and sedimentation into a red-brown and dark-brown liquids (Chalermsan and Peerapan, 2009),(Kiarie-Makara, et al., 2010). Generally, the major components of wood vinegar are acetic acid and methanol while acetone, methyl acetone, acetaldehyde, allyl alcohol, furan and furfural, and formic, propionic 
and butyric acids among others are also present (Tiilikkala, et al., 2010). On the other hand, wood tar generally consists of aldehydes, ketones, acids, and esters compounds.

Wood vinegar from various plants like inner coconut shell, bamboo and eucalyptus woods have been useful as coalescing and antifungal agents for natural rubber substituting the commercial acids like acetic and formic (Baimark and Niamsa, 2009). This was viable since the wood vinegars tested yielded higher coalescing and antifungal efficiencies than the commercial ones depending on their phenolic compositions (Chalermsan and Peerapan, 2009). Similarly, wood vinegar and tar have been used as insects (mosquitos, butterflies and caterpillars), termites and molluscs repellant. They have been used as a biocides successfully without any notable environmental effect because of their high acetic acid contents (Kiarie-Makara, et al., 2010), (Tiilikkala, et al., 2010), (Masum, et al., 2013),(Pangnakorn, et al., 2012).

Masum et al. (2013) and Pangnakorn et al. (2012) noted that wood vinegar essentially increases the soil microbial population when applied on the soil thus stimulating plant root growth while offering plant immunity against diseases. Similarly, they observed that spraying leaves of plants with wood vinegar helps strengthen the stems and makes the leaves greener and tolerant to pest and diseases thereby increasing crop yield. According to Mungkunkamchao et al. (2013), Petter, et al. (2013) and Masum, et al. (2013) mixing wood vinegar with the commercial fertilizers proportionately have had positive effects on the overall yield of tomatoes, rice, wheat, maize, soybeans among other cereal crops thus making wood vinegar an excellent soil conditioner.

In addition, wood vinegar has been used as wood preservative against discoloration and as feed-stuffs for weaning piglets by improving their digestion through curbing toxic coliforms from accumulating in the intestines. On the other hand, wood tar has also been used as an herbicide to control several weed species in bedding plants for several centuries (Tiilikkala, et al., 2010). Therefore, the banana wastes vinegar and tar from this research was evaluated to ascertain the chemical components whether they too could be useful in agriculture and chemical industry and thus recommended for use in Uganda. This would be very important since no published literature on utilization of banana vinegar and tar on the above named uses exists.

\section{Materials and Methods}

\subsection{Materials}

The study was carried out in Uganda at Makerere University Agricultural Research Institute Kabanyolo (MAURIK) agricultural engineering workshop. The institute is located along latitude $0.45^{\circ}$ and longitude $32.62^{\circ}$ about $21 \mathrm{~km}$ north of Kampala in Wakiso district. The research utilized the available banana pseudostem and leaf wastes from the agricultural banana farm specifically the mpologoma, kisansa and kibuzi species. Wet banana peels were randomly selected from the students' canteen kitchen.

\subsection{Slow Pyrolysis of Banana Wastes Biomass}

The pyrolysis process for the banana wastes was done using a steel batch reactor of capacity 37.6 litres designed and built at the University of Kentucky Appropriate Technology Sustainability Research group (UKATS) (Joshi and Seay, 2016). The reactor system had two condensation stages for the heavy gases and the less dense gases while the NCGs were channeled through a pipe and collected separately. The fuel source for heating the reactor was dry firewood heated at a constant average rate of $10^{\circ} \mathrm{C} / \mathrm{min}$. The dried pieces of banana wastes biomass feedstock were weighed on an electronic scale between $200-800 \mathrm{~g}$ before being fed into the reactor. The reactor was then heated to desired temperature ranges of $350-550^{\circ} \mathrm{C}$ while varying the residence time between $45-90$ minutes according to the experimental design variables (Jourabchi, et al., 2014).

The gases and vapours formed were collected through the double stage condensation. The first condensation point collected a heavy and dark liquid (tar) while the second point a light brown liquid (wood vinegar). The vinegar and tar formed were collected in two different plastic containers before being weighed and stored. The biochar (black substances) remained in the reactor and was collected after cooling. However, the NCG and waste water were channeled through a pipe and collected in air tight polythene bags.

\subsection{Characterization of the Liquids}

\subsubsection{Gas Chromatograph (GC) Analysis Methodology}

To analyze the chemical class composition of the wood vinegar and tar samples collected from the banana biomass wastes, a gas chromatograph (GC) model 7820A from Agilent Technologies was utilized. Experiments were conducted using an Agilent DB-624 UI column with a length of $30 \mathrm{~m}$, diameter of $0.250 \mathrm{~mm}$, and film thickness of $1.40 \mu \mathrm{m}$. The GC was equipped with a flame ionization detector (FID). The temperature program began with an initial temperature of $35^{\circ} \mathrm{C}$, held for 1 minute, then helium was used to carry the gas ramped at 
$120^{\circ} \mathrm{C}$ /minute to $26^{\circ} \mathrm{C}$ and held for 10 minutes, for a total run time of 34 minutes. This was repeated for all the samples and the results were displayed in chromatograms which were then printed out for interpretations and analysis. The peaks identification was done by matching the retention times of the chromatographic column samples with the standard National Institute of Standards and Technology (NIST) library retention times of known wood vinegar and tar compounds.

\subsubsection{Physicochemical Analysis Methodology}

The physicochemical properties of the vinegar and tar samples were analyzed using simple laboratory methods. Banana leaves vinegar (run 15) and tar (run 1) both at $450^{\circ} \mathrm{C}$, banana pseudostem vinegar (run 1) at $613.3^{\circ} \mathrm{C}$ and $\operatorname{tar}\left(\right.$ run 8) at $286.7^{\circ} \mathrm{C}$ and banana peels vinegar (run 13) at $450^{\circ} \mathrm{C}$ and tar (run 9) at $286.7^{\circ} \mathrm{C}$ were used. The densities of both the vinegars and tars were determined by taking the ratios of mass $(\mathrm{g})$ and volumes $\left(\mathrm{cm}^{3}\right)$. Similarly, the $\mathrm{pH}$ values for all the samples were determined using a laboratory $\mathrm{pH}$ meter HI $2215 \mathrm{pH} / \mathrm{ORP}$ Meter model. The dynamic viscosity of vinegar and tar samples were determined using the Haake-Falling-Ball Höppler viscosimeter at room temperature. A Kugel ball of diameter $15.8 \mathrm{~mm}$, weight of $4.937 \mathrm{~g}$, density 2.392 $\mathrm{g} / \mathrm{cm}^{3}$ and constant (k) 0.0168 was lowered carefully into the Höppler viscosimeter tube filled with either tar or vinegar. Finally, the dynamic viscosities were calculated from the following Höppler Eq. 1.

$$
\eta=K \cdot\left(\rho_{s}-\rho_{l}\right) \cdot t
$$

Where: $\boldsymbol{\eta}=$ dynamic viscosity (mPa.s), $\rho_{\mathrm{s}}=$ density of the ball $\left(\mathrm{g} / \mathrm{cm}^{3}\right), \rho_{1}=$ density of the studied liquid $\left(\mathrm{g} / \mathrm{cm}^{3}\right)$, $\mathrm{t}=$ average time to move through the column (seconds) and $\mathrm{K}=$ viscosimeter constant.

Consequently, the kinematic viscosity, $\mathrm{v}\left(\mathrm{m}^{2} / \mathrm{s}\right)$ and fluidity, $\boldsymbol{\varphi}$, were determined from the dynamic viscosity. The kinematic viscosity is the ratio of the individual sample fluid dynamic viscosity and their densities while the fluidity is the inverse of the dynamic viscosities.

Further, the pyrolytic solid contents of both vinegar and tar were determined in the laboratory by weighing the liquid samples and then filtering them using paper filters. The resultant filtered liquid was then reweighed and the difference taken to be the solid matter content. The weights were expressed in percentage wet basis in reference to the initial weight of the vinegar and tar samples.

\section{Results and Discussions}

\subsection{GC Analysis Results}

Figure 1-6 show the GC analysis chromatograms of the three banana samples vinegar and tar. The chromatograms were obtained by scanning the signals peaks according to their retention time while the percentage compound content was determined through the peak area normalization method. The peak areas were not direct indicators of high concentration but reflected the samples organic distribution patterns (Fan, et al., 2014). The principle compounds identified from the banana leaves, pseudostem and peels chromatograms were alcohols, ketones, acids, furans and phenols. There were a total of 15 compounds identified in all the chromatograms analysis. This was totaling to over $80 \%$ of the relative chemical compositions of the tar and vinegar that were successfully identified. 


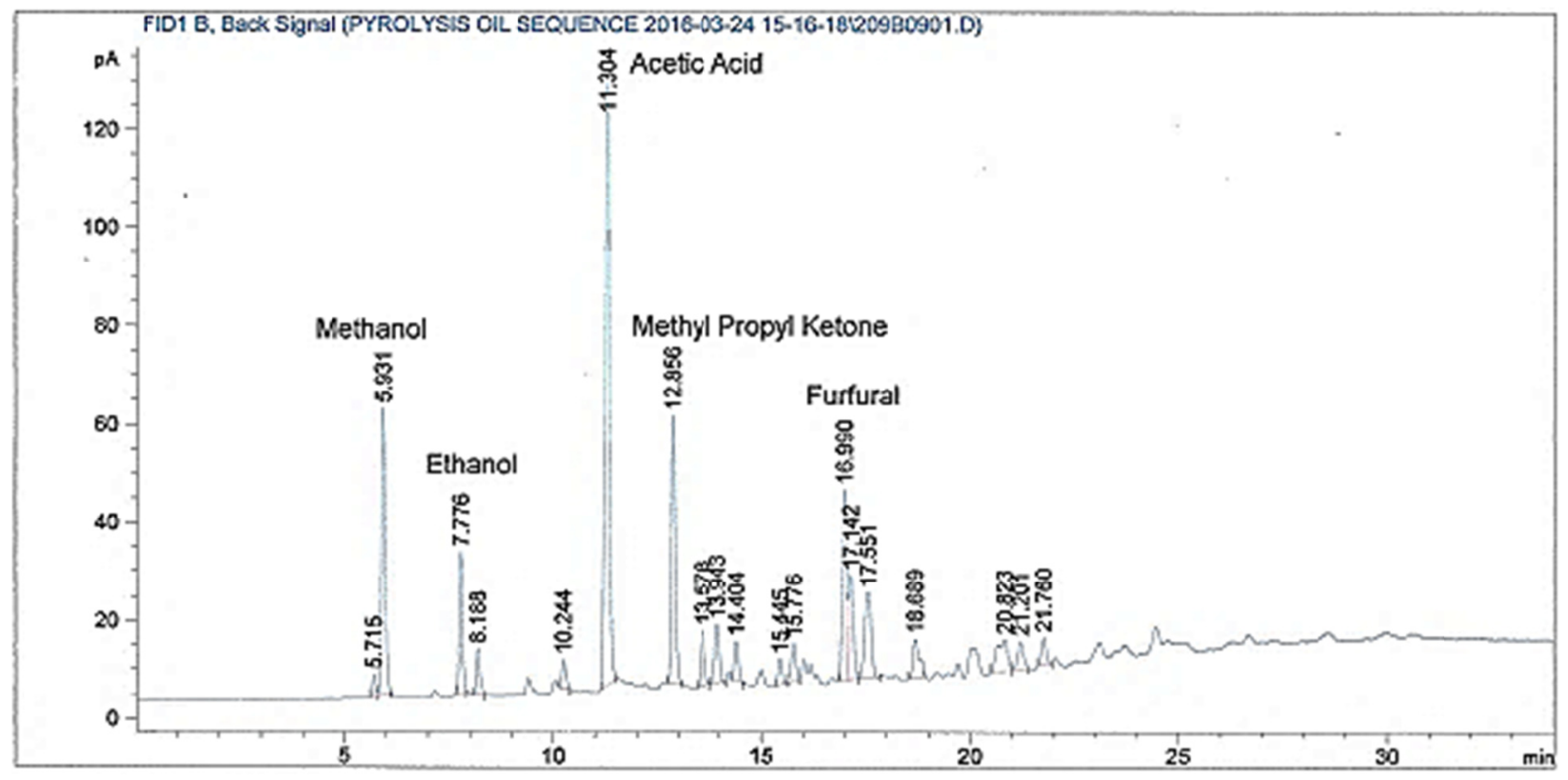

Figure 1. A GC chromatogram of wood vinegar for banana leaves

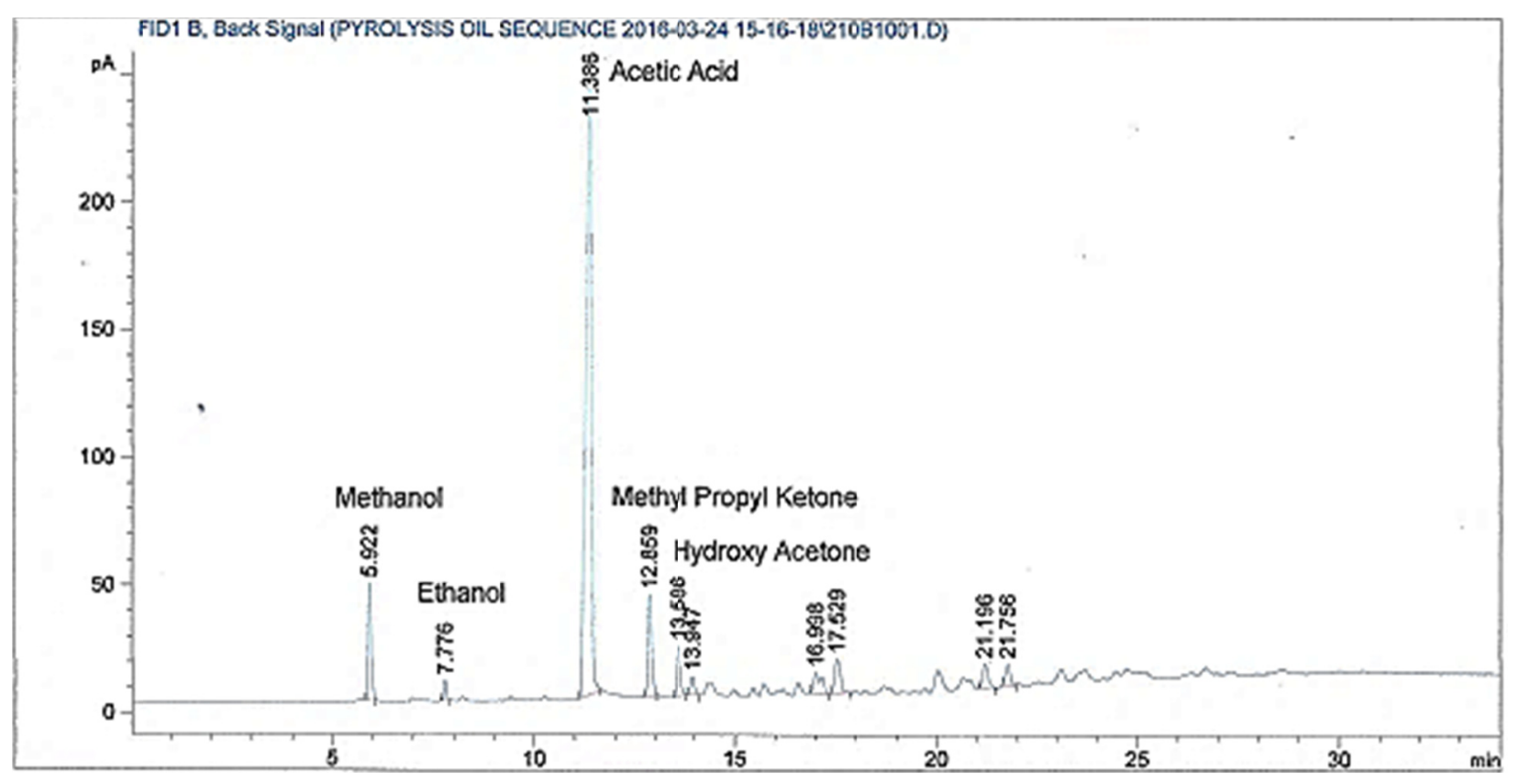

Figure 2. A GC chromatogram of banana leaves tar 


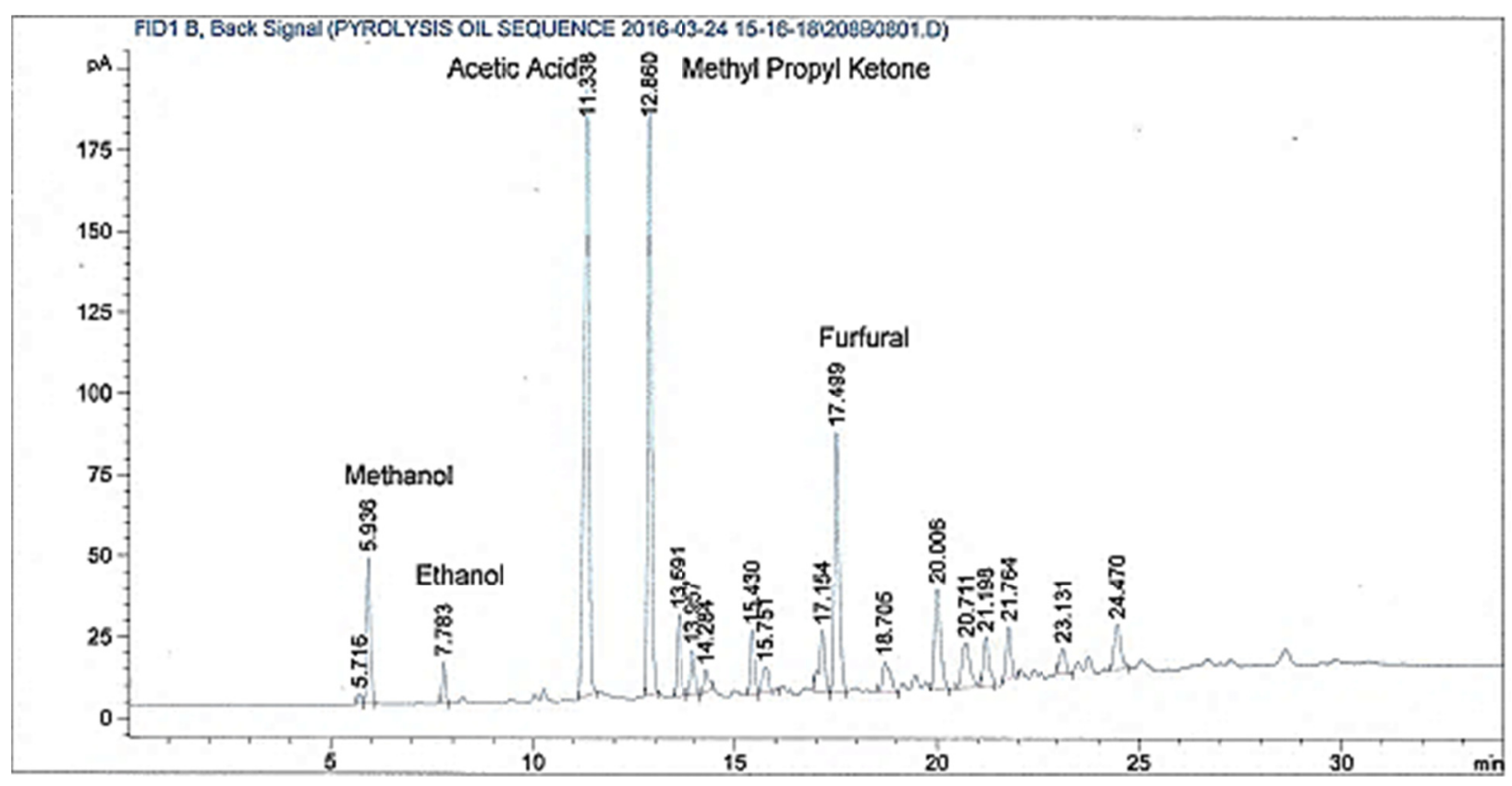

Figure 3. A GC chromatogram of wood vinegar for banana pseudostem

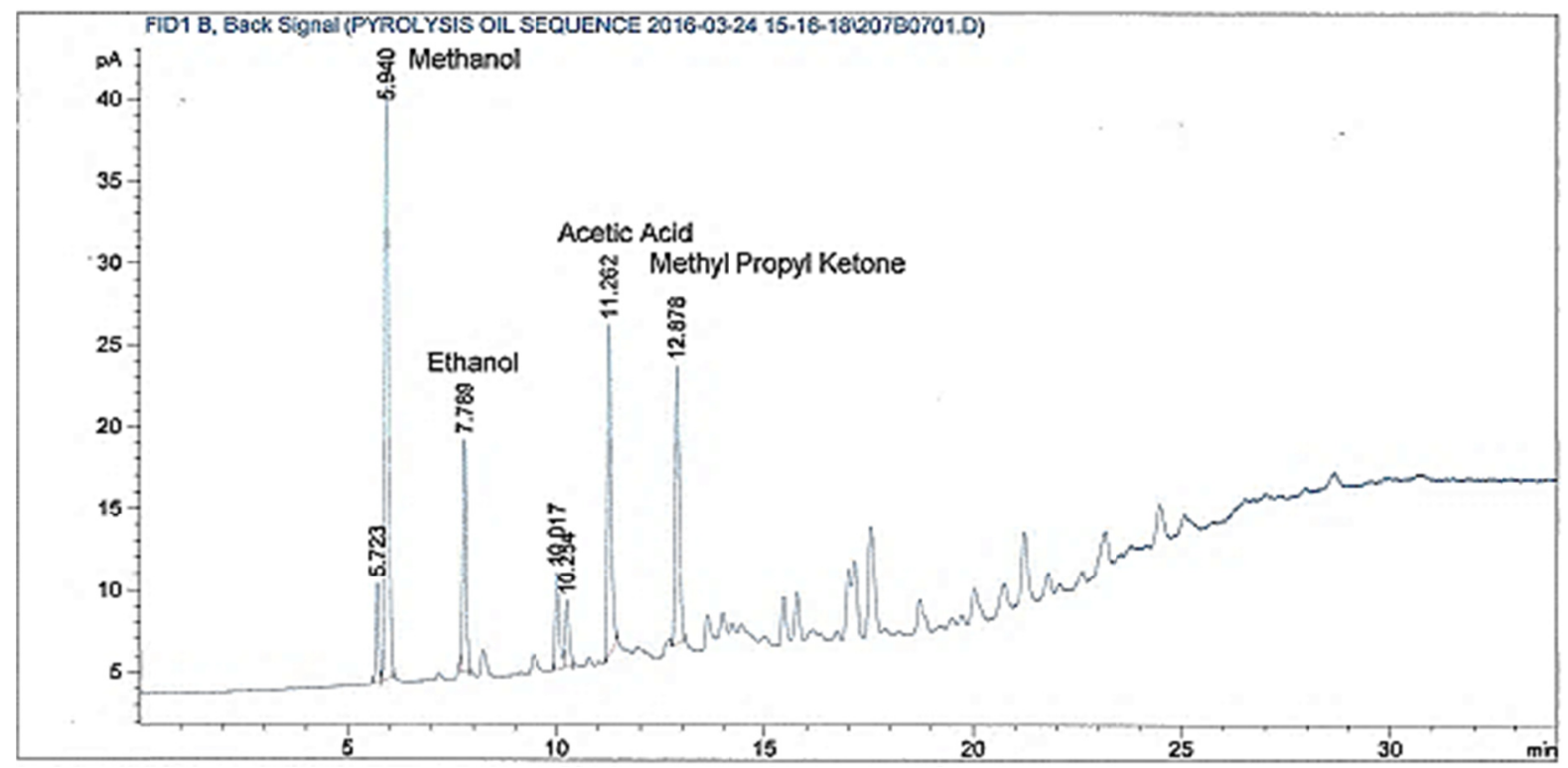

Figure 4. A GC chromatogram of banana pseudostem tar 


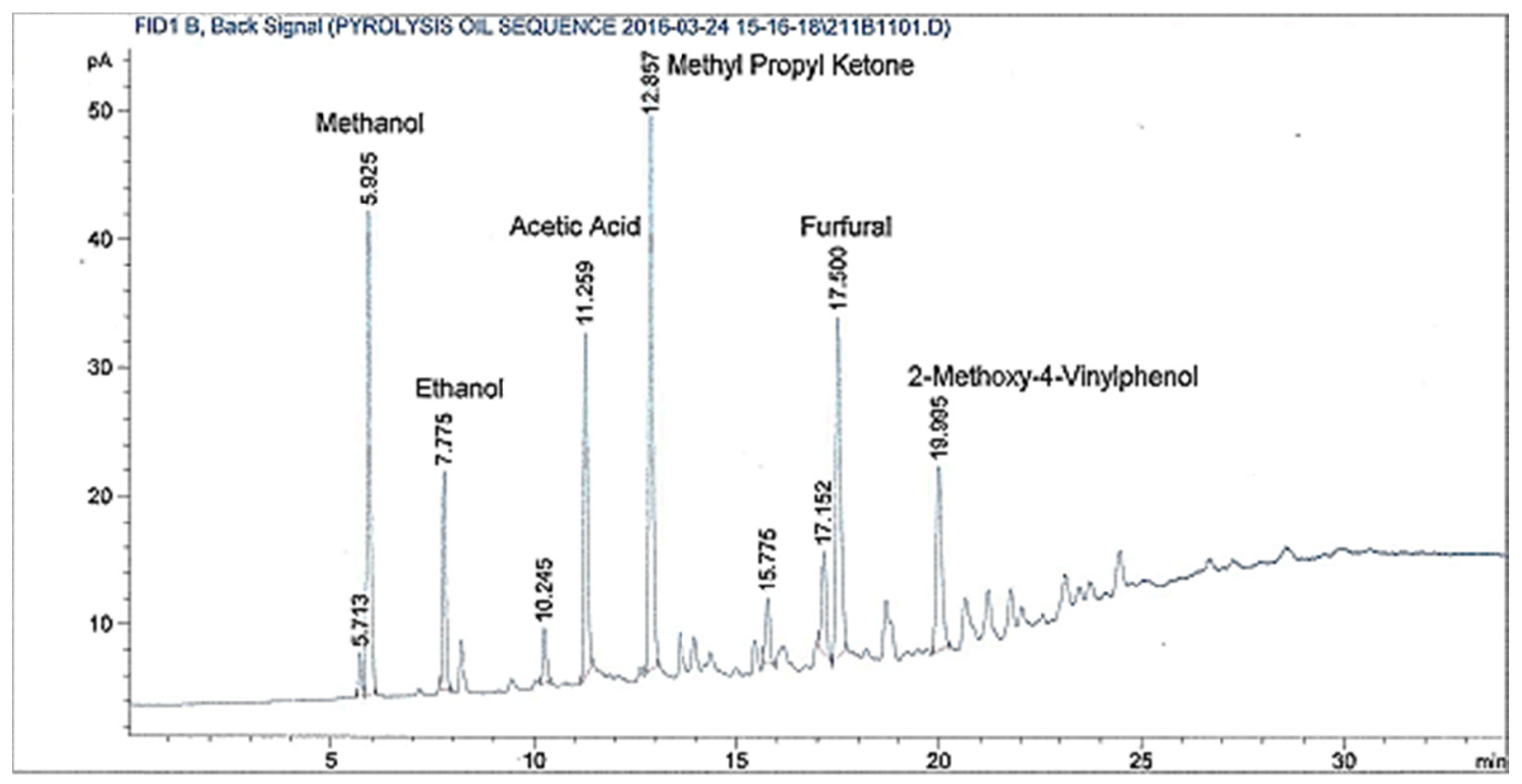

Figure 5. A GC chromatogram of wood vinegar for banana peels

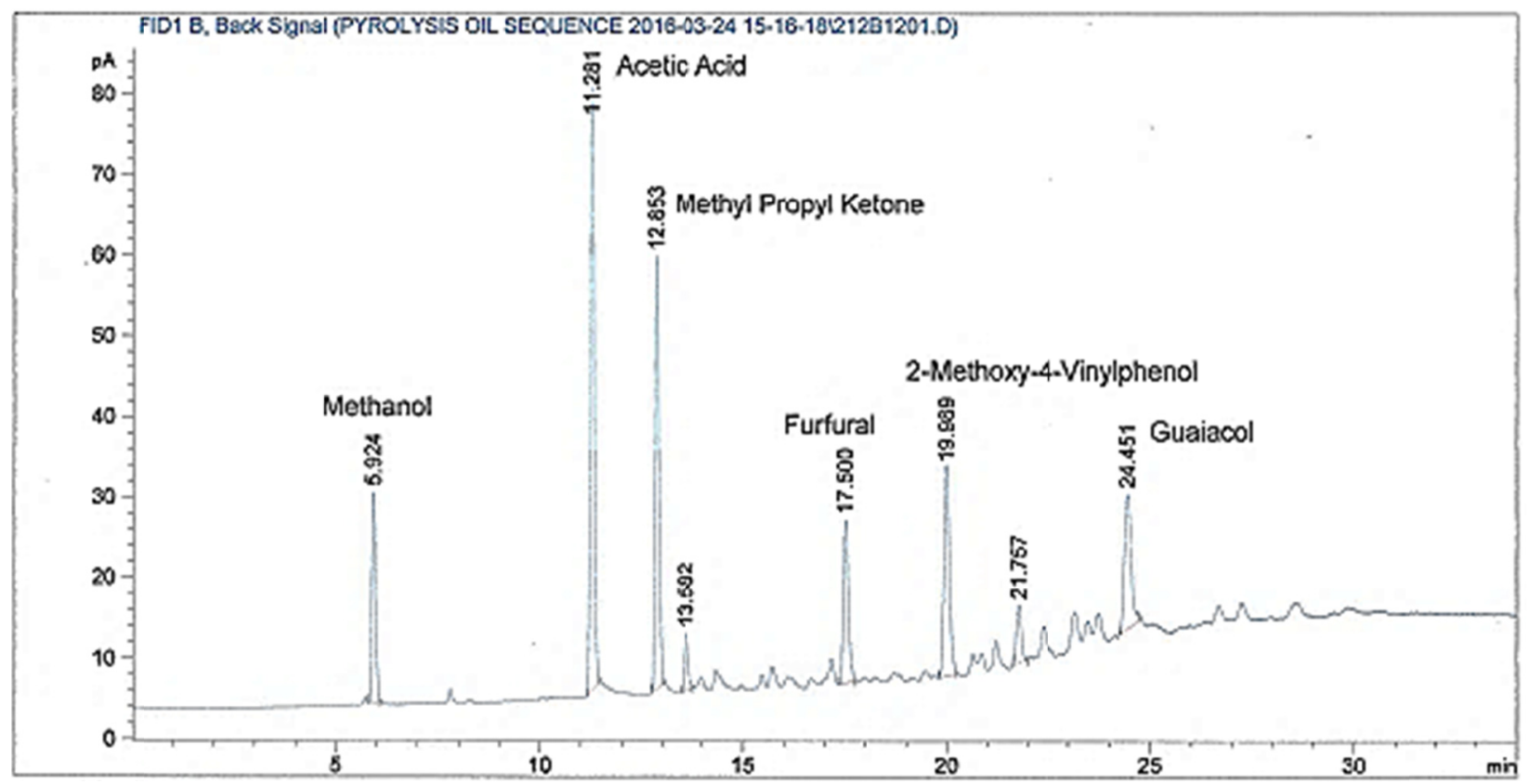

Figure 6. A GC chromatogram of banana peels tar

GC analysis is a very fast and efficient techniques used to evaluate different complex organic compounds in pyrolytic oils. Equally, it enables further understanding of the connection between different components during the pyrolysis process and their analytical variations (Wang, et al., 2011). The vinegar and tar yields from pyrolysis of various biomass feedstock are characterized to ascertain the similarity they have with the already existing vinegar and fossil fuel products (Çepelioğullar and Pütün, et al., 2014). In addition, the environmental pollution and greenhouse effect concerns also fosters the need for analysis of the chemical composition of banana wastes vinegar and tar.

According to Lee et al. (2013), the main hydrocarbon groups resulting from a slow pyrolysis are alcohols, ketones, acids, furans and phenols a fact which was also true for banana wastes vinegar and tar. Thus, the principle components of banana samples vinegar and tar were acetic acid, methanol, furfural, 
methyl-propyl-ketone (MPK), propanoic acid, acetone, 3-hexanone, ethanol, allyl alcohol, hydroxy acetone, cyclohexanol, 2-methoxy-4-vinylphenol, octanol, benzyl alcohol and guaiacol as illustrated in

Table 1. Among these, the highest compound products were acetic acid (67.06\%) in banana leaves tar, methanol $(40.36 \%)$ in banana pseudostem vinegar and methyl propyl ketone $(23.57 \%)$ in banana peels vinegar. The carbon chain length from the vinegar and tar compounds were in the range of $\mathrm{C} 1-\mathrm{C} 8$ while the molar mass was ranging from $32-150 \mathrm{~g} / \mathrm{mol}$.

Table 1 also indicates the GC peak area (\%) of different components of the banana wastes samples vinegar and tar based on the percentage wet mass basis.

Table 1. The main identified compounds of banana Leaves, Pseudostem and Peels Vinegar and Tar by GC analysis combined

\begin{tabular}{|c|c|c|c|c|c|c|c|c|c|c|}
\hline \multirow[b]{2}{*}{ * RT } & \multirow[b]{2}{*}{ Compounds } & \multirow[b]{2}{*}{ Group } & \multirow[b]{2}{*}{$\begin{array}{l}\text { Chemical } \\
\text { Formula }\end{array}$} & \multirow{2}{*}{$\begin{array}{l}\text { Molar } \\
\text { Mass } \\
\text { (g/mol) }\end{array}$} & \multicolumn{6}{|c|}{ \% Peak Area } \\
\hline & & & & & $* * \mathbf{B L V}$ & BLT & BSV & BST & BPV & BPT \\
\hline 5.931 & Methanol & Alcohol & $\mathrm{CH}_{3} \mathrm{HO}$ & 32.04 & 12.10 & 7.36 & 40.36 & 5.12 & 19.16 & 9.26 \\
\hline 7.776 & Ethanol & Alcohol & $\mathrm{C}_{2} \mathrm{H}_{5} \mathrm{OH}$ & 46.07 & 4.81 & 1.15 & 12.15 & 1.16 & 7.14 & - \\
\hline 8.188 & Acetone & Ketone & $\mathrm{CH}_{3} \mathrm{COCH}$ & 58.08 & 1.87 & - & - & - & - & - \\
\hline & & & 3 & & & & & & & \\
\hline 10.244 & Allyl Alcohol & Alcohol & $\mathrm{C}_{3} \mathrm{H}_{6} \mathrm{O}$ & 58.08 & 1.20 & - & 9.95 & - & 2.08 & - \\
\hline 11.304 & Acetic Acid & Acid & $\mathrm{CH}_{3} \mathrm{COOH}$ & 60.05 & 28.94 & 67.06 & 19.72 & 28.54 & 12.94 & 28.62 \\
\hline 12.856 & $\begin{array}{l}\text { Methyl Propyl } \\
\text { Ketone }\end{array}$ & Ketone & $\mathrm{C}_{5} \mathrm{H}_{10} \mathrm{O}$ & 86.13 & 11.27 & 7.43 & 17.83 & 20.90 & 23.57 & 23.01 \\
\hline 13.578 & $\begin{array}{l}\text { Hydroxy } \\
\text { Acetone }\end{array}$ & Ketone & $\mathrm{C}_{3} \mathrm{H}_{6} \mathrm{O}_{2}$ & 74.08 & 2.43 & 3.94 & - & 3.07 & - & - \\
\hline 14.404 & Propionic acid & Acid & $\mathrm{C}_{3} \mathrm{H}_{6} \mathrm{O}_{2}$ & 74.08 & 4.67 & 1.51 & - & 2.76 & - & - \\
\hline 15.776 & 3-Hexanone & Ketone & $\mathrm{C}_{6} \mathrm{H}_{12} \mathrm{O}$ & 100.16 & 3.08 & - & - & 3.60 & 2.71 & - \\
\hline 17.551 & Furfural & Furan & $\mathrm{C}_{5} \mathrm{H}_{4} \mathrm{O}_{2}$ & 96.09 & 20.15 & 6.98 & - & 14.81 & 21.81 & 9.80 \\
\hline 18.689 & Cyclohexanol & Phenol & $\mathrm{C}_{6} \mathrm{H}_{12} \mathrm{O}$ & 100.16 & 2.69 & - & - & - & - & - \\
\hline 20.823 & $\begin{array}{l}\text { 2-Methoxy-4- } \\
\text { Vinylphenol }\end{array}$ & Phenol & $\mathrm{C}_{9} \mathrm{H}_{10} \mathrm{O}_{2}$ & 150.17 & 3.53 & - & - & 13.60 & 10.59 & 14.21 \\
\hline 21.201 & Octanol & Alcohol & $\mathrm{C}_{8} \mathrm{H}_{17} \mathrm{OH}$ & 130.23 & 3.26 & 4.57 & - & 2.29 & - & 3.58 \\
\hline 23.131 & $\begin{array}{l}\text { Benzyl } \\
\text { Alcohol }\end{array}$ & Alcohol & $\mathrm{C}_{7} \mathrm{H}_{8} \mathrm{O}$ & 105.14 & - & - & - & 1.27 & - & - \\
\hline 24.470 & Guaiacol & Phenol & $\mathrm{C}_{7} \mathrm{H}_{8} \mathrm{O}_{2}$ & 124.14 & - & - & - & 2.85 & - & 11.52 \\
\hline
\end{tabular}

* Retention time

** BLV (banana leaves vinegar), BLT (banana leaves tar), BSV (banana pseudostem vinegar), BST (banana pseudostem tar), BPV (banana peels vinegar) and BPT (banana peels tar)

In general, the most abundant compounds considering the percentage peak areas were the acids $(68.6 \%)$ followed by alcohols (62.5\%), ketones (27.6\%), phenols (25.7\%), and furans $(21.8 \%)$ as can be seen in Figure 7 . According to Wang et al. (2011) and Ningbo et al. (2015), acids, aldehydes and furans are products of biomass hemicellulose while the phenols the products of lignin polymerization. The distribution of the compounds in the banana leaves, pseudostem and peels for vinegar and tar in terms of the percentage peak areas varied as is represented in Figure 8-10. Ultimately, acetic acid and methanol were the major components of the three samples' vinegar and tar as illustrated by their high peak area percentages (Figure 8-10). 


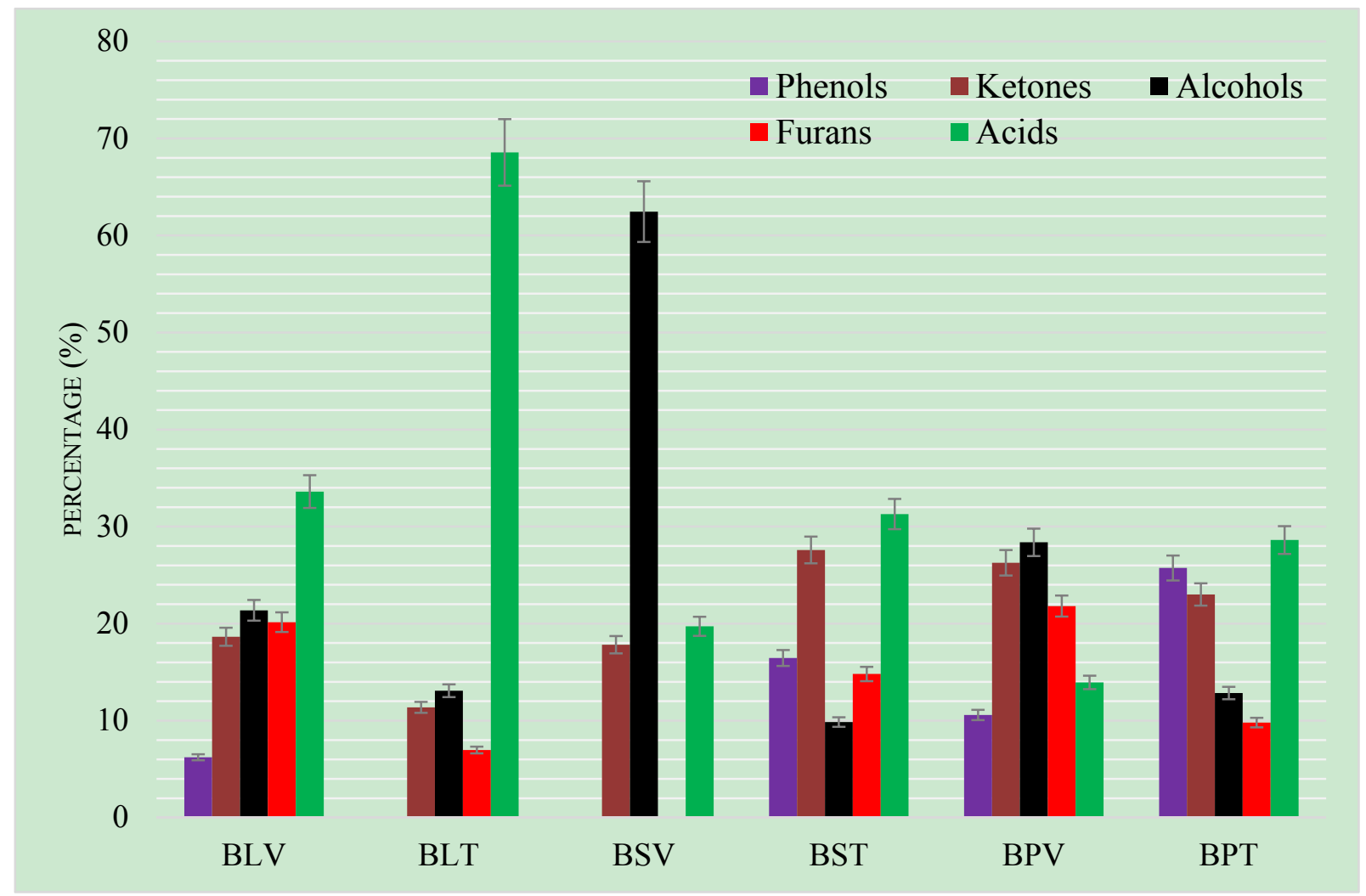

Figure 7. Abundant compounds in all the banana samples vinegar and tar

Where: BLV - banana leaves vinegar, BLT - banana leaves tar, BSV - banana pseudostem vinegar, BST banana pseudostem tar, BPV - banana peels vinegar and BPT - banana peels tar.

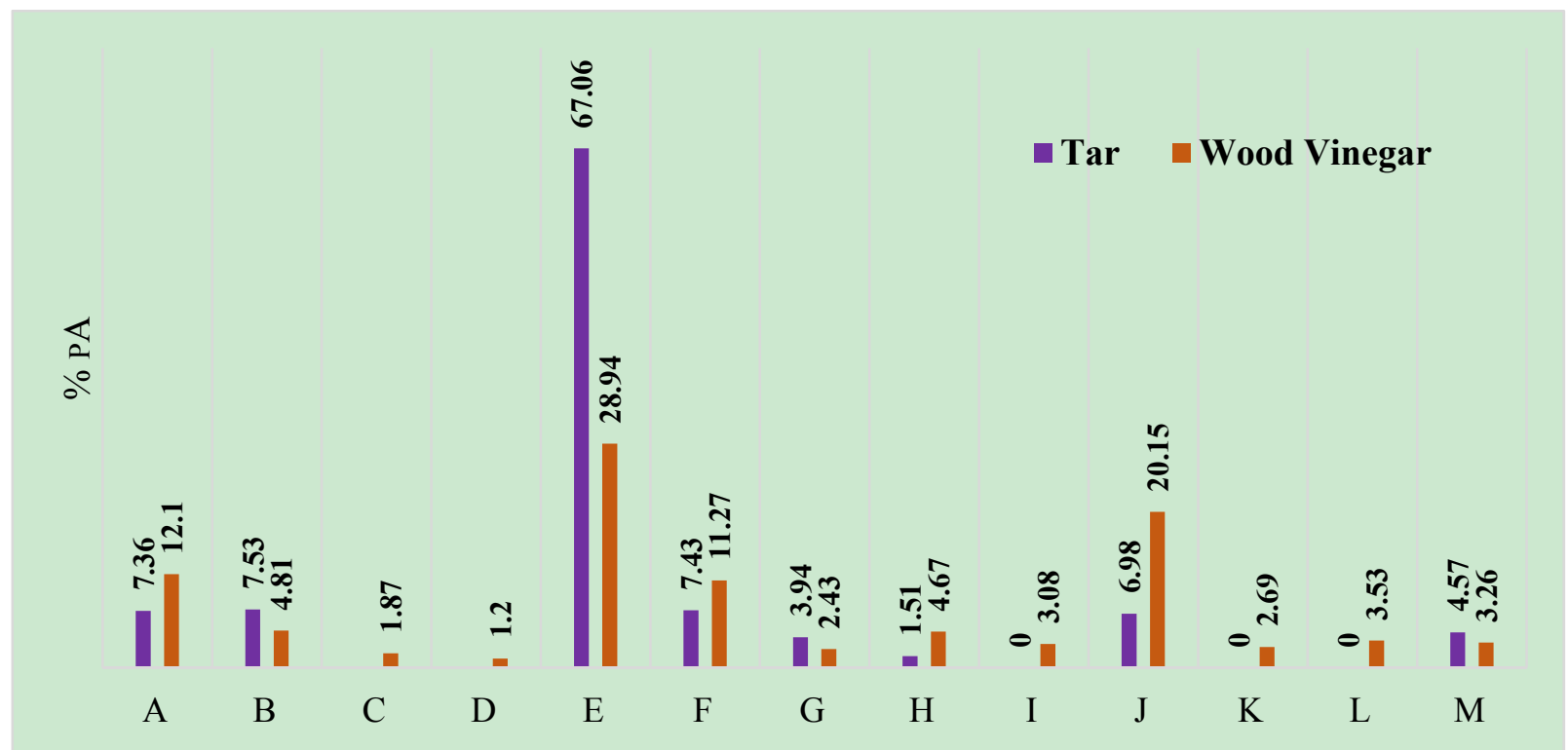

Figure 8. Chemical compounds of banana leaves vinegar and tar considering the percentage pick area

Where: A: Methanol, B: Ethanol, C: Acetone, D: Allyl Alcohol, E: Acetic Acid, F: Methyl Propyl Ketone, G: Hydroxy Acetone (Acetol), H: Propionic acid, I: 3-Hexanone, J: Furfural, K: Cyclohexanol, L: 2-Methoxy-4-Vinylphenol and M: Octanol. 


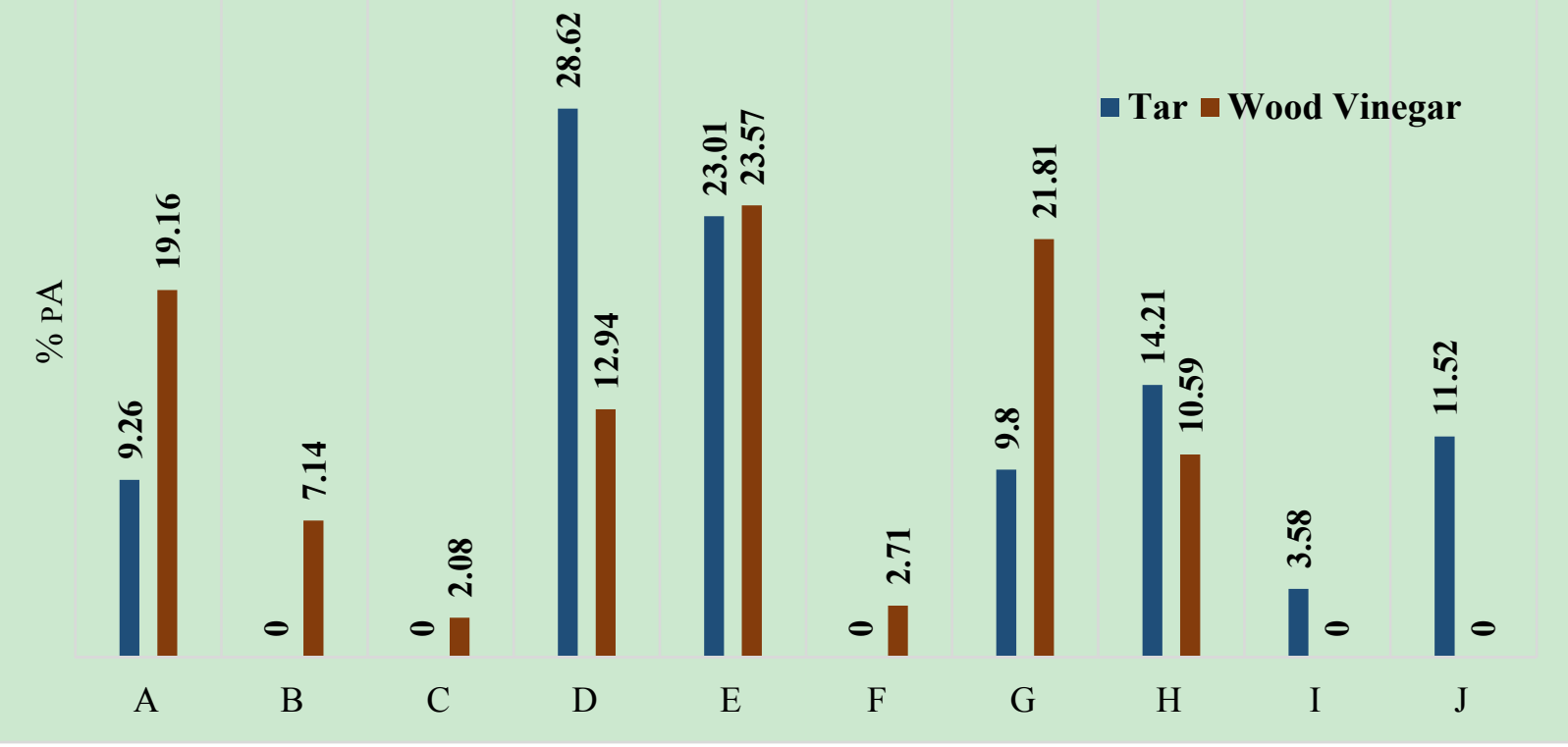

Figure 9. Chemical compounds of banana stem vinegar and tar considering the percentage pick area

Where: A: Methanol, B: Ethanol, C: Allyl Alcohol, D: Acetic Acid, E: Methyl Propyl Ketone, F: Hydroxy Acetone (Acetol), G: Propionic Acid, H: 3-Hexanone, I: Furfural, J: 2-Methoxy-4-Vinylphenol, K: Octanol, L: Benzyl Alcohol and M: Guaiacol.

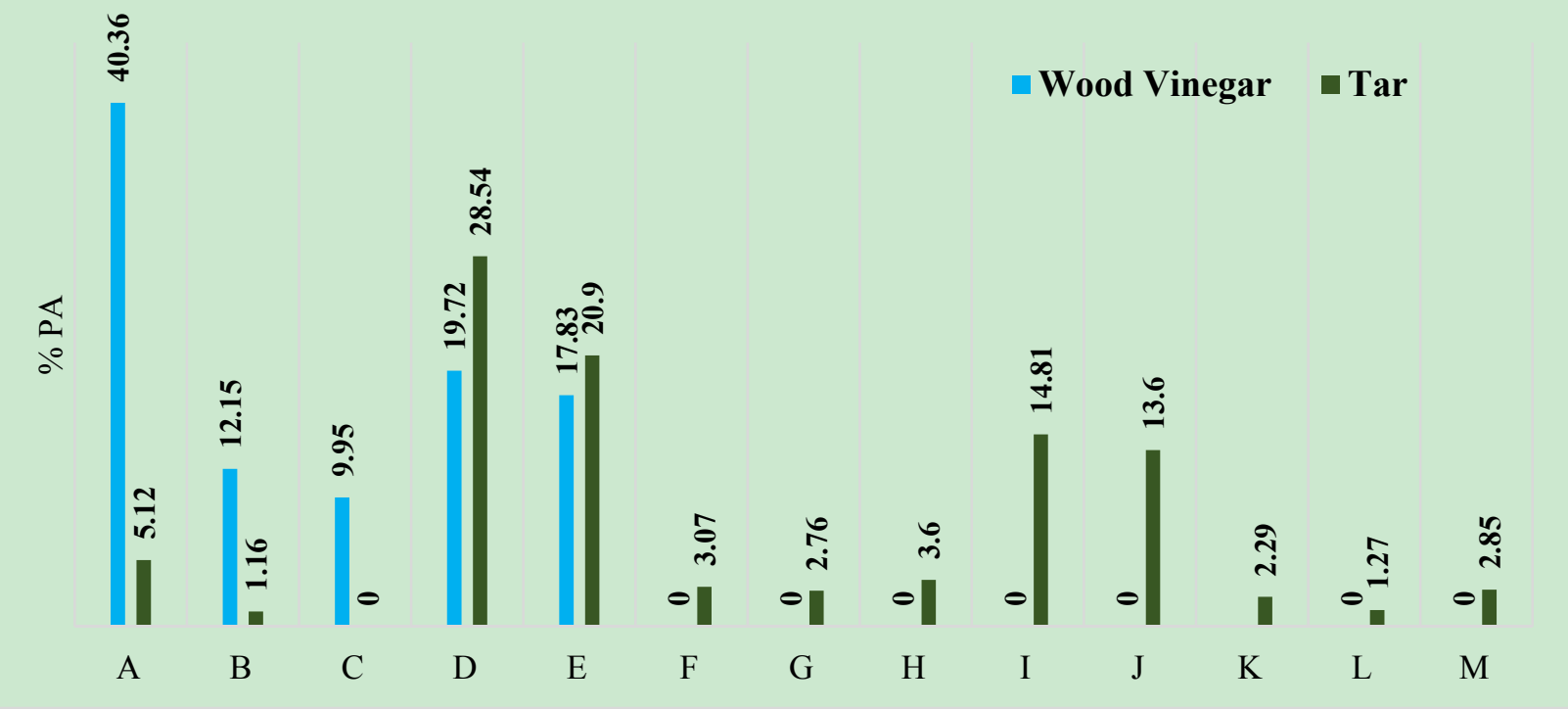

Figure 10. Chemical compounds of banana peels vinegar and tar considering the percentage pick area

Where: A: Methanol, B: Ethanol, C: Allyl Alcohol, D: Acetic Acid, E: Methyl Propyl Ketone, F: 3-Hexanone, G: Furfural, H: 2-Methoxy-4-Vinylphenol, I: Octanol and J: Guaiacol.

Consequently, according to Fan et al. (Fan, et al., 2014), alcohol, phenols and furans compounds are useful products in biofuels production as well as in added value chemicals in various processes. The presence of the acids, ketones and aldehydes in bio-oils are fairly detrimental since acids leads to corrosion while ketones and aldehydes causes volatility during transport or storage. However, the absence of compounds like ethers, esters 
and oxygenates make the heating values of the vinegar and tar potentially higher than other bio-oils that have them.

\subsection{Physicochemical Characteristics of Banana Wastes Pyrolysis Liquids}

The values of the various physical and chemical properties of the vinegar and tar analyzed as density, dynamic and kinematic viscosities, fluidity, $\mathrm{pH}$ value and solid matter content as given in Table 2 . The densities of the bio-oils were higher than water (averagely $1.1 \mathrm{~g} / \mathrm{cm}^{3}$ ) thus analogous to other bio-oils from other biomasses like softwood bark $\left(1.1-1.2 \mathrm{~g} / \mathrm{cm}^{3}\right)$ (Mohan, et al., 2006) among others. The dynamic viscosity varied between $1.1-$ $1.2 \mathrm{mPa} . \mathrm{s}$ which is higher than the waters' viscosity while the kinematic viscosity varied from $1.0-1.1 \mathrm{~m}^{2} / \mathrm{s}$.

Table 2. Physicochemical properties of banana samples vinegar and tar

\begin{tabular}{lcccccc}
\hline $\begin{array}{l}\text { Banana } \\
\text { Sample }\end{array}$ & $\begin{array}{c}\text { Density } \\
\left(\mathbf{g} / \mathbf{c m}^{\mathbf{3}}\right)\end{array}$ & $\begin{array}{c}\text { *Dynamic } \\
\text { Viscosity }(\mathbf{m P a . s})\end{array}$ & $\begin{array}{c}\text { Kinematic } \\
\text { Viscosity }\left(\mathbf{m}^{\mathbf{2}} \mathbf{s}\right)\end{array}$ & Fluidity & $\mathbf{p H}$ & **SC (\%) \\
\hline Leaves Vinegar & 1.106 & 1.0733 & 0.9707 & 0.9317 & 5.59 & 5.15 \\
Leaves Tar & 1.081 & 1.1747 & 1.0866 & 0.8513 & 3.53 & 6.48 \\
Stem Vinegar & 1.062 & 1.2070 & 1.1370 & 0.8285 & 4.67 & 3.89 \\
Stem Tar & 1.084 & 1.2230 & 1.1279 & 0.8177 & 3.46 & 4.65 \\
Peels Vinegar & 1.114 & 1.0663 & 0.9570 & 0.9379 & 4.23 & 3.66 \\
Peels Tar & 1.089 & 1.2043 & 1.1062 & 0.8304 & 4.02 & 3.67 \\
\hline
\end{tabular}

*Viscosity at room temperature $26.4^{\circ} \mathrm{C}$

** Percentage solid content in wet basis

The vinegar and tar viscosities were lower than most bio-oils produced by other biomass feedstocks. This implied that there can be utilized as engine fuels if properly upgraded as they can easily atomize and burn. The lower viscosities were appreciably contributed to by the high amount of water present in the vinegar and tar indicated by the high fluidity values (Fan, et al., 2014). The $\mathrm{pH}$ values denoted that banana biomass vinegar and tar were acidic (3.5-5.6). This was chiefly due to the presence of acetic and propanoic acid compounds (Ratanapisit, et al., 2009). The $\mathrm{pH}$ range was akin to literature values of other biomass bio-oils like the softwood bark (3.0), rice straw (3.0-3.3), sugarcane bagasse (2.0-2.3) and coconut shell (3.1-3.3) (Mohan, et al., 2006) (Tsai, et al., 2006) among others.

\subsection{Potential Applications of Banana Wastes Vinegar and Tar}

According to Baimark and Niamsa (Baimark and N. Niamsa, 2009) and Hagner (2013), the presence of acetic acid, furfurals and phenolic compounds are strong indicators that wood vinegar can be used as anti-germinating agents, pesticides, termiticide and fungicides. Similarly, in a study carried to investigate the utilization of pyrolysis vinegar and tar from birch wood, Hagner (Hagner, 2013) found out that the presence of acetic acid and furfural compounds made them effective repellant for snails (molluscs). Wood vinegar has been applied in various concentrations as mosquito repellant (Culex pipiens pallens Coquillet, Culex quinquefasciatus Say \& Aedes togoi Theobald) both in the laboratory and field tests with significant success (Kiarie-Makara, et al., 2010),(Pangnakorn, et al., 2011). Furthermore, Pangnakorn et al. (2012) noted that the applications of different wood vinegar concentrations on adult or larvae housefly had very lethal effects resulting in deformation of adult flies and inhibition of larvae growth. These successful tests were due to chemical compounds that the various wood vinegars harbor which include acetic acid, ketones, phenols, alcohols and furans among others.

Contrariwise, studies also show that wood vinegar has been used as anti-leaching and soil degradation agents (Hagner, et al., 2013), soil conditioners and environmental improvement agents (Wu, et al., 2015). Similarly, they been used as fertilizer in Aman rice production (Masum, et al., 2013) as well as tomatoes yield enhancers (Mungkunkamchao, et al., 2013). Thus the effectiveness of wood vinegar and tar use as soil amendment tools is dependant on their chemical compositions. Therefore, the results of GC analysis of the banana wastes vinegar and tar and the presence of ketones, phenols, alcohols and furan compounds denote reliably that banana wastes vinegar and tar can be used in various ways as discussed above. This can be very sustainable for developing countries like Uganda with enormous annual budget for acquiring fertilizer and pest and diseases control chemicals. This can significantly boost the agricultural sector and impact on food insecurity immensely. 


\section{Conclusions}

Based on the GC analysis and physicochemical characterization of the banana wastes vinegar and tar, they harbor vital compounds that are very useful both in agriculture and chemical industries. The chemical composition of the three banana waste biomasses were highly related. Thus, the high presence of acids, ketones, phenols, alcohols and furans compounds in banana wastes vinegar and tar inferred that they could be used as pesticides, insecticides, biocides, antifungal agents and soil conditioners among others. This offers a sustainable solution to farmers, agricultural sectors and chemical industries by utilizing the abundant biomass wastes to manufacture these valuable products. Consequently, this can contribute immeasurably to meeting global goal of zero food insecurity especially in developing and under developed countries.

\section{Acknowledgements}

Special thanks to METEGA project and RUFORUM for their financial support.

\section{References}

Baimark, Y., \& Niamsa, N. (2009). Study on wood vinegars for use as coagulating and antifungal agents on the production of natural rubber sheets. Biomass and Bioenergy, 33(6-7), 994-998. https://doi.org/10.1016/j.biombioe.2009.04.001

Brewer, C. E., Schmidt-Rohr, K., Satrio, J. A., \& Brown, R. C. (2009). Characterization of Biochar from Fast Pyrolysis and Gasification Systems. Environ. Prog. Sustain. Energy, 28(3), 386-396. https://doi.org/10.1002/ep.10378

Çepelioğullar, Ö., \& Pütün, A. E. (2014). Products characterization study of a slow pyrolysis of biomass-plastic mixtures in a fixed-bed reactor. J. Anal. Appl. Pyrolysis, 110, 363-374. https://doi.org/10.1016/j.jaap.2014.10.002

Chalermsan, Y., \& Peerapan, S. (2009). Wood vinegar: by-product from rural charcoal kilns and its role in plant protection. Asian J. Food AGro-Industry, (189-195), 189-195.

Fan, Y., Cai, Y., Li, X., Yin, H., Yu, N., Zhang, R., \& Zhao, W. (2014). Rape straw as a source of bio-oil via vacuum pyrolysis : Optimization of bio-oil yield using orthogonal design method and characterization of bio-oil. J. Anal. Appl. Pyrolysis, (106), 63-70. https://doi.org/10.1016/j.jaap.2013.12.011

FAO. (2013). Food and Agriculture Organization of the United Stations.

Hagner, M. (2013). Potential of the slow pyrolysis products birch tar oil, wood vinegar and biochar in sustainable plant protection - pesticidal effects, soil improvement and environmental risks. University of Helsinki Finland.

Hagner, M., Penttinen, O., Tiilikkala, K., \& Setälä, H. (2013). The effects of biochar, wood vinegar and plants on glyphosate leaching and degradation. Eur. J. Soil Biol., (58), 1-7. https://doi.org/10.1016/j.ejsobi.2013.05.002

Joshi, C. A., \& Seay, J. R. (2016). An Appropriate Technology Based Solution to Convert Waste Plastic into Fuel Oil in Underdeveloped Regions. J. Sustain. Dev., 9(4), 133. https://doi.org/10.5539/jsd.v9n4p133

Jourabchi, S. A., Gan, S., \& Ng, H. K. (2014). Pyrolysis of Jatropha curcas pressed cake for bio-oil production in a fixed-bed system. Energy Convers. Manag., 78, 518-526. https://doi.org/10.1016/j.enconman.2013.11.005

Kan, T., Strezov, V., \& Evans, T. J. (2016). Lignocellulosic biomass pyrolysis: A review of product properties and effects of pyrolysis parameters. Renew. Sustain. Energy Rev., 57, 1126-1140. https://doi.org/10.1016/j.rser.2015.12.185

Kiarie-Makara, M. W., Yoon, H., \& Lee, D. (2010). Repellent efficacy of wood vinegar against Culex pipiens pallens and Aedes togoi (Diptera: Culicidae) under laboratory and semi-field conditions. Entomol. Res., 40, 97-103. https://doi.org/10.1111/j.1748-5967.2010.00265.x

Lee, Y., Park, J., Ryu, C., Gang, K. S., Yang, W., Park, Y. K. ... Hyun, S. (2013). Comparison of biochar properties from biomass residues produced by slow pyrolysis at $500^{\circ} \mathrm{C}$. Bioresour. Technol., 148, 196-201. https://doi.org/10.1016/j.biortech.2013.08.135

Masum, S. M., Malek, M., Mandal, M. S. H., Haque, M. N., \& Akther, Z. (2013). Influence of Plant extracted Pyroligneous Acid on transplanted Aman rice. J. Exp. Biosci., 4(2), 31-34.

Mohan, D., Pittman, C. U., \& Steele, P. H. (2006). Pyrolysis of Wood / Biomass for Bio-oil: A Critical Review. 
Energy \& Fuels, 20(4), 848-889. https://doi.org/10.1021/ef0502397

Mungkunkamchao, T., Kesmala, T., Pimratch, S., Toomsan, B., \& Jothityangkoon, D. (2013). Wood vinegar and fermented bioextracts: Natural products to enhance growth and yield of tomato (Solanum lycopersicum L.). Sci. Hortic. (Amsterdam)., 154, 66-72. https://doi.org/10.1016/j.scienta.2013.02.020

Ningbo, G., Baoling, L., Aimin, L., \& Juanjuan, L. (2015). Continuous pyrolysis of pine sawdust at different pyrolysis temperatures and solid residence times. J. Anal. Appl. Pyrolysis, 114, 155-162. https://doi.org/10.1016/j.jaap.2015.05.011

Omulo, G., Banadda, N., \& Kiggundu, N. (2015). Harnessing of banana ripening process for banana juice extraction in Uganda. African J. Food Sci. Technol., 6(4), 108-117.

Pangnakorn, U., Kanlaya, S., \& Kuntha, C. (2011). Efficiency of wood vinegar and extracts from some medicinal plants on insect control. Adv. Environ. Biol., 5(2), 477-482.

Pangnakorn, U., Kanlaya, S., \& Kuntha, C. (2012). Effect of Wood Vinegar for Controlling on Housefly (Musca domestica L.). World Acad. Sci. Eng. Technol., 6(5), 374-377.

Petter, F. A., Silva, L. B., Souza, I. J., Magionni, K., Pacheco, L. P., Almeida, F. A., \& Pavan, B. E. (2013). Adaptation of the Use of Pyroligneous Acid in Control of Caterpillars and Agronomic Performance of the Soybean Crop. J. Agric. Sci., 5(8), 27-36. https://doi.org/10.5539/jas.v5n8p27

Ratanapisit, J., Apiraksakul, S., Rerngnarong, A., Chungsiriporn, J., \& Bunyakarn, C. (2009). Preliminary evaluation of production and characterization of wood vinegar from rubberwood. Songklanakarin J. Sci. Technol., 31(3), 343-349.

Tiilikkala, K., Fagernäs, L., \& Tiilikkala, J. (2010). History and use of wood pyrolysis liquids as biocide and plant protection product. Open Agric. J, 111-118. https://doi.org/10.2174/1874331501004010111

Tripathi, M., Sahu, J. N., \& Ganesan, P. (2016). Effect of process parameters on production of biochar from biomass waste through pyrolysis: A review. Renew. Sustain. Energy Rev., 55, 467-481. https://doi.org/10.1016/j.rser.2015.10.122

Tsai, W. T., Lee, M. K., \& Chang, Y. M. (2006). Fast pyrolysis of rice straw, sugarcane bagasse and coconut shell in an induction-heating reactor. J. Anal. Appl. Pyrolysis, 76(1-2), 230-237. https://doi.org/10.1016/j.jaap.2005.11.007

Uganda Bureau of Statistics (UBS). (2014). Statistical Abstract, 2014. Kampala, Uganda.

Wang, S., Guo, X., Wang, K., \& Luo, Z. (2011). Influence of the interaction of components on the pyrolysis behavior of biomass. J. Anal. Appl. Pyrolysis, 91(1), 183-189. https://doi.org/10.1016/j.jaap.2011.02.006

Wu, Q., Zhang, S., Hou, B., Zheng, H., Deng, W., Liu, D., \& Tang, W. (2015). Study on the preparation of wood vinegar from biomass residues by carbonization process. Bioresour. Technol., 179, 98-103. https://doi.org/10.1016/j.biortech.2014.12.026

Yorgun, S., \& Yildiz, D. (2015). Slow pyrolysis of paulownia wood: Effects of pyrolysis parameters on product yields and bio-oil characterization. J. Anal. Appl. Pyrolysis, 114, 68-78. https://doi.org/10.1016/j.jaap.2015.05.003

\section{Copyrights}

Copyright for this article is retained by the author(s), with first publication rights granted to the journal.

This is an open-access article distributed under the terms and conditions of the Creative Commons Attribution license (http://creativecommons.org/licenses/by/4.0/). 